\title{
On the use of deep convective clouds to calibrate AVHRR data
}

\author{
David R. Doelling $^{* a}$, Louis Nguyen ${ }^{\mathrm{b}}$, Patrick Minnis ${ }^{\mathrm{b}}$ \\ ${ }^{a}$ Analytical Services and Materials, Inc., One Enterprise Pkwy Ste 300, Hampton, VA 23666 USA \\ 'NASA Langley Research Center, 21 Langley Blvd MS 420, Hampton, VA 23681-2199 USA
}

Earth Observing Systems IX Conference

International Symposium on Optical Science and Technology

SPIE $49^{\text {th }}$ Annual Meeting

Denver, $\mathrm{CO}$

2-6 August 2004 


\title{
On the use of deep convective clouds to calibrate AVHRR data
}

\author{
David R. Doelling ${ }^{{ }^{a}}$, Louis Nguyen ${ }^{\mathrm{b}}$, Patrick Minnis ${ }^{\mathrm{b}}$ \\ ${ }^{a}$ Analytical Services and Materials, Inc., One Enterprise Pkwy Ste 300, Hampton, VA 23666 USA \\ ${ }^{\mathrm{b}}$ NASA Langley Research Center, 21 Langley Blvd MS 420, Hampton, VA 23681-2199 USA
}

\begin{abstract}
Remote sensing of cloud and radiation properties from National Oceanic and Atmospheric Administration (NOAA) Advanced Very High Resolution Radiometer (AVHRR) satellites requires constant monitoring of the visible sensors. NOAA satellites do not have onboard visible calibration and need to be calibrated vicariously in order to determine the calibration and the degradation rate. Deep convective clouds are extremely bright and cold, are at the tropopause, have nearly a Lambertian reflectance, and provide predictable albedos. The use of deep convective clouds as calibration targets is developed into a calibration technique and applied to NOAA-16 and NOAA-17. The technique computes the relative gain drift over the life-span of the satellite. This technique is validated by comparing the gain drifts derived from inter-calibration of coincident AVHRR and Moderate-Resolution Imaging Spectroradiometer (MODIS) radiances. A ray-matched technique, which uses collocated, coincident, and co-angled pixel satellite radiance pairs is used to intercalibrate MODIS and AVHRR. The deep convective cloud calibration technique was found to be independent of solar zenith angle, by using well calibrated Visible Infrared Scanner (VIRS) radiances onboard the Tropical Rainfall Measuring Mission (TRMM) satellite, which precesses through all solar zenith angles in 23 days.
\end{abstract}

Keywords: Calibration, AVHRR, MODIS, Visible, Deep Convective Clouds

\section{INTRODUCTION}

There are many Advanced Very High Resolution Radiometer (AVHRR) products that require well-calibrated visible channel radiances. Cloud and aerosol optical depth measurements, vegetation indices, and land classification parameters are sensitive to calibration drifts over time. They are also affected by the individual absolute calibration coefficients used on each of the NOAA satellites. There are 26 years of National Oceanic and Atmospheric Administration (NOAA) AVHRR pixel level radiances that are archived, which could potentially be used to provide a climatology of cloud, radiation and surface products. These radiances could be used to study changes in the Earth's climate, assuming that they can be reliably calibrated. There have been many published post-launch AVHRR calibration coefficients derived by vicarious calibration. These include, stable desert ${ }^{1}$ and polar ice ${ }^{2}$ targets, congruent aircraft calibration, ${ }^{3}$ and intercalibration of satellites with onboard calibration ${ }^{4}$. It would be ideal if a method can be consistently applied to all historical AVHRR data. Deep convective clouds are cold bright targets, which produce consistent albedos, making them well suited for calibration. The deep convective clouds technique (DCCT) requires no ancillary data and uses a simple IR threshold to identify the convective clouds. All AVHRR infrared (IR) channels have onboard blackbodies that provide accurate 10.8- $\mu \mathrm{m}$ temperatures. The method, if applied to AVHRR radiances, also needs to take into account changes in solar zenith angle over time due to orbital degradation. If the DCCT has sufficiently robust angular dependence correction models, this should not be a significant error source. The DCCT can provide the relative gain drift over time but it does not provide an absolute calibration. The absolute calibration can be transferred using wellcalibrated satellite imagers, such as the Moderate-Resolution Imaging Spectroradiometers (MODIS) on Terra and Aqua, by inter-calibration of ray-matched radiances that are coincident and collocated. These radiances occur at ground track intersections near the poles. Since NOAA satellites are always launched in AM and PM pairs, the absolute calibration can be transferred between them using the same ray-matched technique given a long enough time period of overlap. This should be possible beginning with NOAA-9 and NOAA-10 in 1985. The relative differences in gain between NOAA AM and PM pairs have been computed using the polar matched data ${ }^{5}$. Both the NOAA AM and PM pair calibration transfer and the DCCT can be validated concurrently by taking the ratio of the AM-PM pair gain to the DCCT gains and comparing them with the gain obtained through inter-calibration. Further validation can be obtained from calibration coefficients in previous publications. This approach has the potential for providing reliable AVHRR calibrations from NOAA-9 to the present.

*d.r.doelling@larc.nasa.gov; phone 1.757.827.4634; http://www-pm.larc.nasa.gov 


\section{DEEP CONVECTIVE CLOUD CALIBRATION}

\subsection{Methodology}

The DCCT used here is similar to the one outlined by Hu et. al (2004) ${ }^{6}$ who demonstrated that deep convective clouds have a constant monthly mean albedo over the lifetime (January - August 1998) of the Clouds and the Earth's Radiant Energy System (CERES) instrument onboard the Tropical Rainfall Measuring Mission (TRMM) satellite. This assumption can only be made if the CERES radiances are properly calibrated and do not drift over time. The CERES instrument is absolutely calibrated with a thermister bolometer that uses a package of onboard blackbodies, lamps, space and solar looks. ${ }^{7}$ The CERES instrument is calibrated to within $1 \%$ in the shortwave and has been shown to be stable over time onboard the TRMM, Terra, and Aqua satellites. The DCCT uses convective clouds as bright earth targets that have a predictable albedo. The amount of cloud reflection at the top of atmosphere is limited by gaseous absorbers, primarily, ozone. The DCCT uses deep clouds rather than a surface target. Most deep clouds are at the tropopause level and hence the effects of water vapor and tropospheric aerosol absorption are minimized. Also the DCCT does not rely on navigation to find its target. In addition, the deep clouds are nearly Lambertian reflectors at low sun angles. The DCCT can be used to observe the relative instrument degradation over time, but a radiative transfer model is still required to obtain an absolute calibration. Large ozone variations and stratospheric aerosols will reduce the accuracy of the method.

NOAA-16 and 17 AVHRR Global Area Coverage (GAC; $3 \mathrm{~km} \mathrm{x} 4 \mathrm{~km}$ ) data were obtained from the NOAA Satellite Active Archive web site. NOAA-16 and NOAA-17 were launched on September 21, 2000 and June 24, 2002, respectively. Data collection began in April 2001 for NOAA-16 and August 2002 for NOAA-17. Every other month through April 2004 was sampled to construct a time series of results. To reduce the data volume, only pixels over the tropical western Pacific $\left(10^{\circ} \mathrm{N}-15^{\circ} \mathrm{S}\right.$ and $\left.95^{\circ} \mathrm{E}-175^{\circ} \mathrm{E}\right)$ were collected. Pixels with IR temperatures less than $205^{\circ} \mathrm{K}$ were chosen as deep convective clouds. Less than $0.5 \%$ of all pixels sampled met this criterion. To reduce the effects of angular sampling, only pixels with a solar and view zenith angles less than $40^{\circ}$ were used and bidirectional and directional factors were applied to normalize the individual radiances to a common set of angles. The bidirectional reflectance correction model was theoretically derived for deep convective clouds ${ }^{6}$ and the CERES directional model factor $^{8}$ for ice clouds with an optical depth of 50 is used to normalize the albedo to a single solar zenith angle. The AVHRR nominal visible calibrations (available at $\mathrm{http}: / \mathrm{www} 2$.ncdc.noaa.gov/docs $/ \mathrm{klm} / \mathrm{html} / \mathrm{d} / \mathrm{app}-\mathrm{d} . \mathrm{htm}$ ) were used to convert counts into radiances. A two-part gain is used for AVHRR on NOAA satellites beginning with NOAA-15. The enhanced low radiance section is used to improve resolution for clear-sky conditions. It is uncertain how the two gains are correlated. For each month of data a probability density function (PDF) of visible radiances was computed after applying angular corrections (Figure 1a). The peaks of the NOAA-17 $0.86-\mu \mathrm{m}$ pixel radiances slowly drift to lower values over the course of 2 years. This drift represents the visible-channel gain degradation. Figure $1 \mathrm{~b}$ shows that the visible radiance peak can be reduced by limiting the standard deviation of the temperature computed from the 8 surrounding pixels. A standard deviation threshold of $1 \mathrm{~K}$ is used here. Two methods of computing the visible degradation are given. The first method uses the mode or peak based on 5 and $3 \mathrm{Wm}^{-2} \mathrm{sr}^{-1} \mu \mathrm{m}^{-1}$ resolutions for the 0.65 and $0.86-\mu \mathrm{m}$ channels, respectively. The second method uses the mean radiance of all pixels. The degradation is then normalized with respect to the mean radiance for the entire time period. The instrument gain is used to keep the monthto-month radiances constant.

\subsection{Results}

The bi-monthly normalized radiances are plotted for NOAA-16 channels $1(0.65 \mu \mathrm{m}$, Figure 2a) and $2(0.86 \mu \mathrm{m}$, Figure 2b) from January 2001 to April 2004 and for NOAA-17 between August 2002 and April 2004 in Figures 2c and d, respectively. The means are the red points and the mode is in black. A linear regression is used to compute the gain over time. There is about a 3\% variation of monthly values about the regression line. Whether the mean or the mode is used the results are nearly the same, indicating the robustness of the method. The relative annual gains are given in Table 1. The DCCT reveals that the channel-2 gain degrades faster than its $0.65-\mu \mathrm{m}$ counterpart for both satellites and that both NOAA-17 channels are degrading faster than NOAA-16. The accuracy of the mode method may be restricted by the resolution of the fixed radiance intervals used to determine the peak radiance, which is evident in Figure $2 \mathrm{~b}$ where 5 bimonthly points in a row have the same value. The mean reflectance can be derived from the DCCT by plotting the 

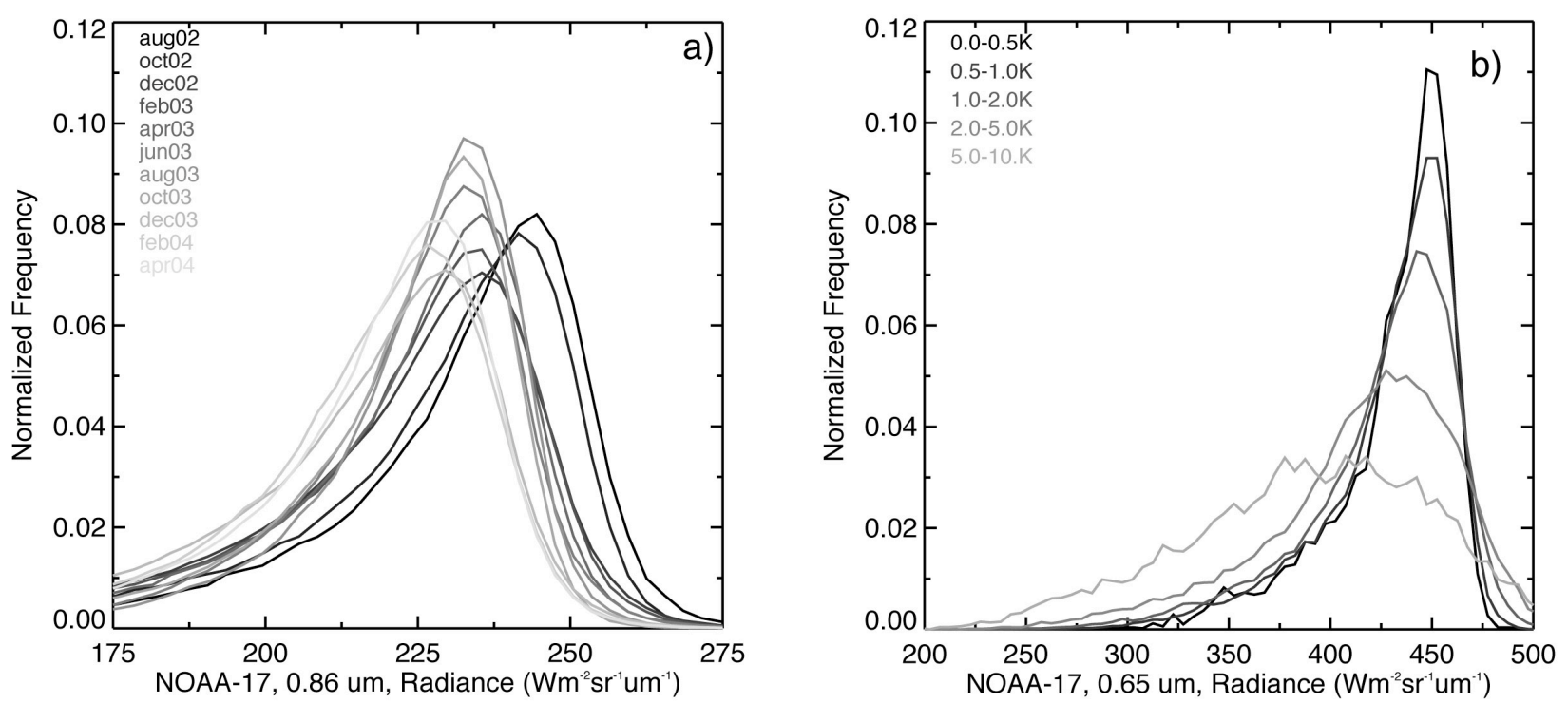

Figure 1: Monthly probability density functions of deep convective cloud NOAA-17 $0.86 \mu \mathrm{m}$ radiances as defined in Sec. 1.1, (a) from August 2002 -April 2004; (b) August 2003, as function of standard deviation of IR temperature of deep convective cloud pixels.

radiances divided by the solar constant rather than the gains. Then, the mean deep convective cloud reflectance at the day of launch can be computed. Assuming that the nominal calibration is accurate, the $0.65-\mu \mathrm{m}$ mean reflectance from the DCCT is 0.83 for NOAA-16 and 0.86 for NOAA-17. For channel 2 , the corresponding values are 0.79 and 0.74 . The spectral response functions of the NOAA-16 and NOAA-17 are nearly identical as shown in Figure 3a. Thus, the differences can only be attributed to the DCCT or the nominal calibration. To determine the technique's reliability, the gains derived from the DCCT will be compared to those derived from inter-calibrating NOAA and MODIS radiances.

\section{INTER-CALIBRATION OF AVHRR AND MODIS}

\subsection{Methodology}

A ray-matching technique is used to inter-calibrate one satellite sensor to another, where the ground tracks of the two satellites intersect at a given time. Pixel radiance pairs that are coincident and have nearly the same angular geometry are used to minimize biases introduced by anisotropic effects. The MODIS has onboard visible calibration using a solar diffuser and has been shown to be stable. ${ }^{9}$ MODIS (MOD0 and MYD0 version 4) 1-km pixel data were obtained from the National Aeronautics and Space Administration (NASA) Langley Distributed Active Archive System (DAAC) at NASA Langley Research Center in Hampton, Virginia. Terra, Aqua, and all NOAA satellites are polar orbiters with morning and afternoon satellite ground tracks intersecting near the poles. For this study NOAA-16 was paired with Terra and NOAA-17 with Aqua. The intersections occur for both combinations near $70^{\circ}$ latitude during the day. The local time is very close to noon, thereby limiting azimuthal angle differences to less than $15^{\circ}$. NOAA-16 and Terra intersect within 2 minutes every 2.2 days. NOAA-17 and Aqua intersect every 3.0 days. Data from 30 intersections were collected centered on March 23, May 23, July 23 and September 23, 2003, where the solar zenith angles are $70^{\circ}, 50^{\circ}$, $50^{\circ}$, and $70^{\circ}$, respectively. The sheer volume of required data limited the number of intersections used in the intercalibrations. The MODIS radiances are normalized to the AVHRR solar constant and solar zenith angles. For both Aqua and Terra, 508.83 and $316.84 \mathrm{Wm}^{-2} \mu \mathrm{m}^{-1} \mathrm{sr}^{-1}$ were used for the 0.65 and $0.86 \mu \mathrm{m}$ channels, respectively. To minimize the effects of navigational errors, pixel radiances were averaged within a $50-\mathrm{km}$ radius of the intersection. ${ }^{5}$

Table 1. Annual relative gains in percent based on the DCCT for NOAA-16 and 17 through April 2004.

\begin{tabular}{ccccc}
\hline DCCT & N16 $0.65 \mu \mathrm{m}$ & $\mathrm{N} 160.86 \mu \mathrm{m}$ & $\mathrm{N} 170.65 \mu \mathrm{m}$ & $\mathrm{N} 170.86 \mu \mathrm{m}$ \\
\hline Mode (\%/year) & 0.796 & 1.43 & 1.43 & 3.50 \\
Mean (\%/year) & 0.840 & 1.16 & 2.19 & 3.55 \\
\hline
\end{tabular}



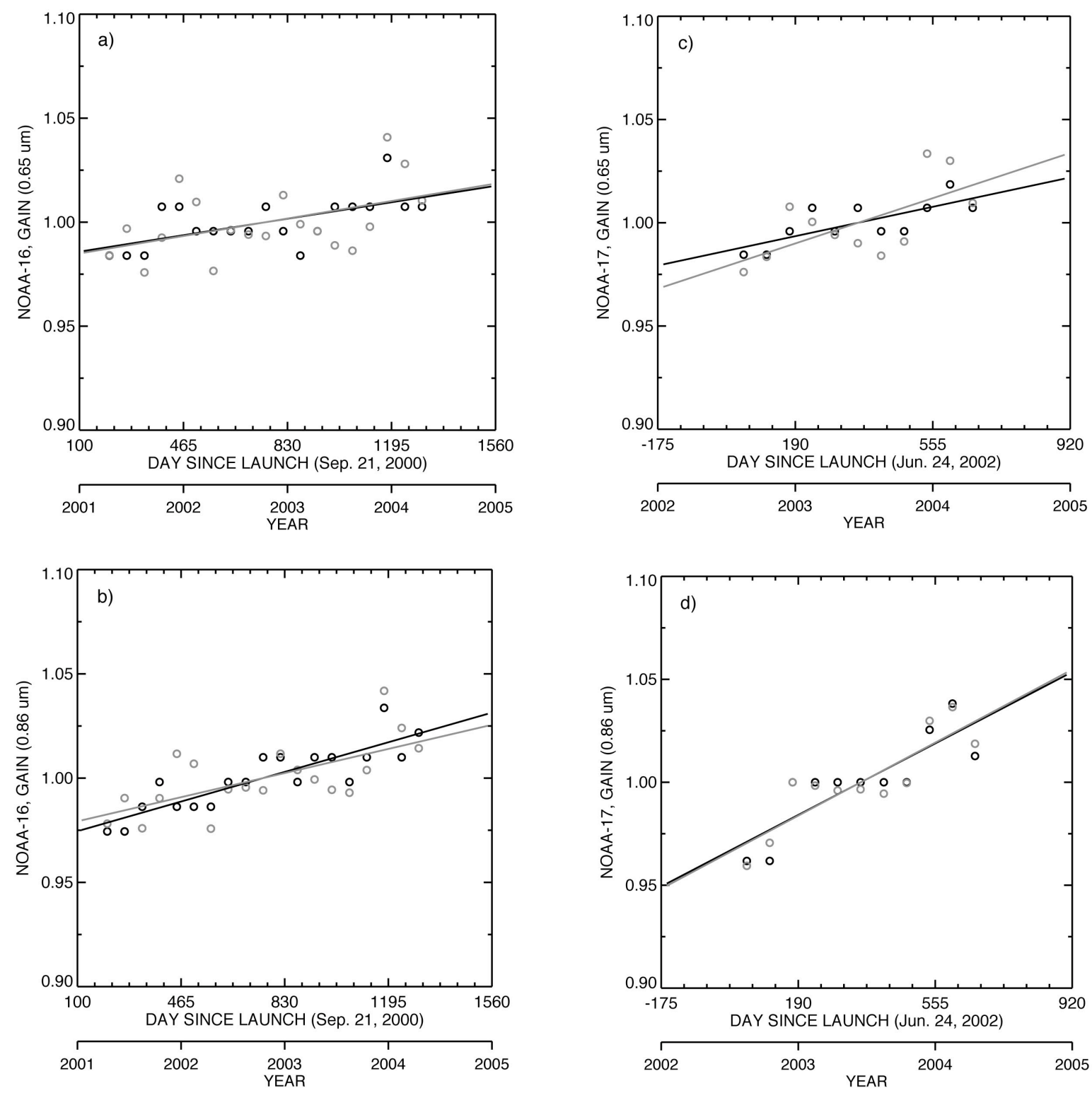

Figure 2: Bi-monthly variation of gain from normalized deep convective cloud reflected radiances with linear regression fits, mode and mean methods shown as solid circles and lines and open circles and dashed lines, respectively (a) NOAA-16 $0.65 \mu \mathrm{m},(\mathrm{b})$ NOAA-16 $0.86 \mu \mathrm{m}$, (c) NOAA-17 $0.65 \mu \mathrm{m}$, (d) NOAA-17 $0.86 \mu \mathrm{m}$.

Two methods are employed here: the first uses only the nadir or intersection points; the second, the off-nadir method, expands the number of samples by using points along a line that have identical view angles between the two ground tracks. The extra off-nadir points are limited by a $7.5^{\circ}$ view zenith angle and do not overlap each other. All AVHRR and MODIS radiance pairs are plotted for a month. A perfect match of radiances would fall along the diagonal. The AVHRR points are plotted along the abscissa so that the slope or gain and offset of the fitted data applied to the AVHRR radiance provides a MODIS-equivalent radiance. The drift in the gain is determined from plots of the time series. Since changes in the offset are inversely correlated with changes in the gain, it is assumed that the offset is invariant since the visible channels have space looks to adjust the offset. A least squares fit to the 0.65 - $\mu \mathrm{m}$ radiances indicates an offset of -0.27 and -0.65 for NOAA- 16 and 17 , respectively, and 1.70 and 1.24 for the corresponding $0.86-$ $\mu \mathrm{m}$ channels. The standard error of the offset is about 2 in these cases and, for now, the offset is assumed to be zero. 

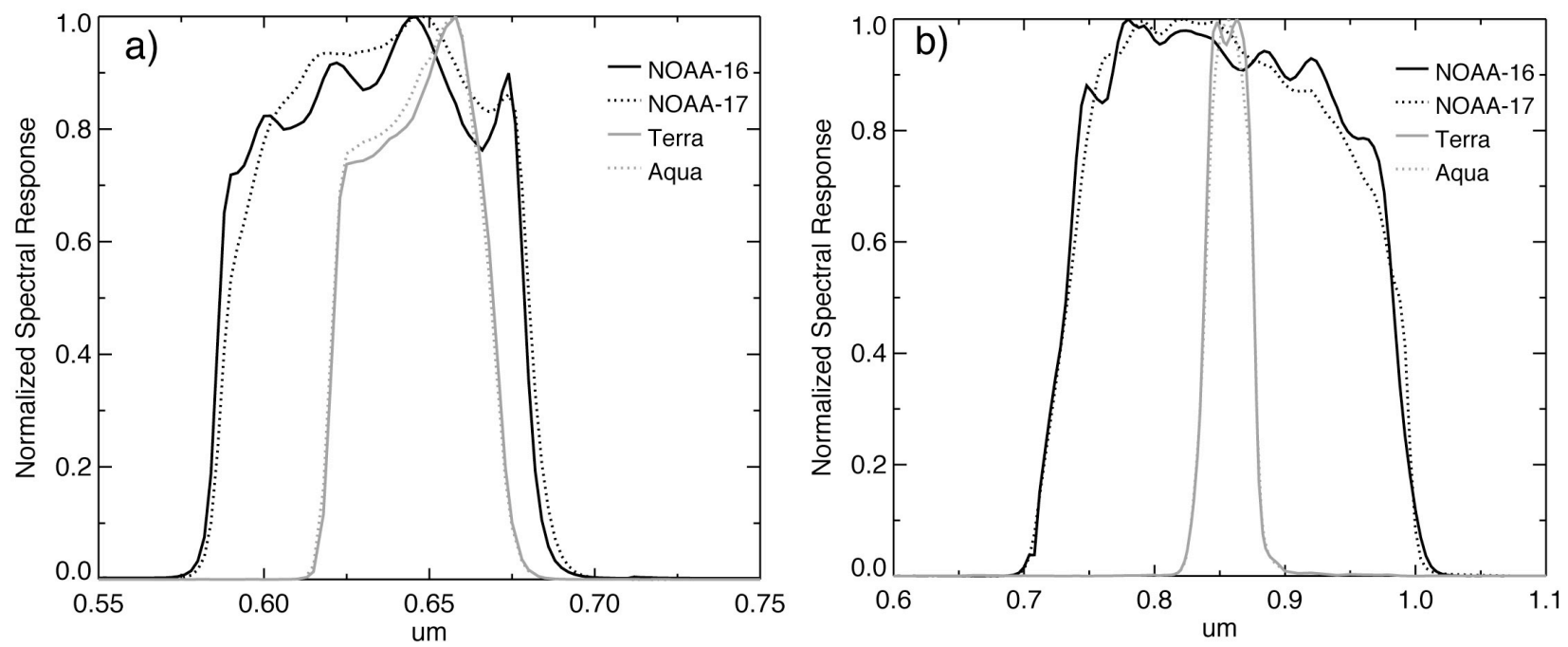

Figure 3: Spectral response functions for AVHRRs and Terra and Aqua MODIS, (a) 0.65- $\mu \mathrm{m}$ channels, (b) $0.86-\mu \mathrm{m}$ channels.

The monthly gain is defined as the slope of a line that intersects the offset point and the mean point of the MODIS and AVHRR radiance pairs.

\subsection{Results}

Figure 4a shows the off-nadir points for the NOAA-17 and Aqua $0.65 \mu \mathrm{m}$ channels for May 2003. The squared correlation coefficient $(R)$ is 0.9989 . All months have $R$ values greater than 0.99 giving credibility to the crosscalibration of NOAA and MODIS. For May 2003 the slopes for the nadir and off-nadir cases are 1.0844 and 1.0830, respectively, but the number of samples has increased 7 times from 24 to 168. The nadir points are a subset of the offnadir points. The inclusion of off-nadir points does not cause greater scatter about the regression line and increases dynamic range. The nominal AVHRR offset, shown in Fig. 4a, seems to be valid. It must be emphasized that spectral differences between NOAA and MODIS visible channels have not been addressed. Part of the radiance differences can be attributed to atmospheric and surface absorption specific to the individual sensors. If both AVHRR and MODIS were calibrated perfectly, a gain greater than unity would indicate greater AVHRR absorption. Figure $3 \mathrm{a}$ and $3 \mathrm{~b}$ show that the NOAA sensors have much larger bandwidths and that both pairs of NOAA and MODIS channels have similar spectral response functions. The MODIS $0.86-\mu \mathrm{m}$ channel is more absorptive. Near the poles, the effects of water vapor absorption should be minimal.

Figure $4 \mathrm{~b}$ shows the effect of the NOAA dual gains, which are not aligned. For radiances less than $100 \mathrm{Wm}^{-2} \mu \mathrm{m}^{-1} \mathrm{sr}^{-1}$ the lower gain seems to fall along the diagonal, while the higher gain is diverges from the diagonal. Only the months of May and July have enough solar energy available to adequately define the upper gain. The future plan is to divide the points between low and high gains and then inter-calibrate. Figure 5 shows the gain trends for NOAA-16/Terra-MODIS and NOAA-17/Aqua-MODIS. The effects of the dual gain are apparent between Figures 5c and 5d. Figure 5c contains regressions similar to Figure $4 \mathrm{a}$ where there is no discontinuity between the dual gains. Figures $5 \mathrm{~d}$ and $5 \mathrm{~b}$ have a disconnect between the two gains. This results in separation of the monthly slopes of May and July of 2003 from the rest of the months. Again, the May and July have the lower solar zenith angles causing the high gain to have a greater effect on the slope of the overall gain. There is greater scatter about the trend line in Figure 5b compared with Figure 5a because of the discontinuity in the channel-2 gains that are not apparent in channel 1.

\subsection{Comparison of inter-calibration and the DCCT}

The DCCT NOAA-16 averages of the mean and mode method annual visible gain trends overestimate the trend by $20 \%$ compared to the inter-calibration of NOAA-16/Terra-MODIS averages of the nadir and off-nadir method gain trends. Given that the range of scatter in the monthly points is greater than the regressed gain trend and that the trend is very small, it could be concluded that the DCCT can be used to calibrate NOAA-16 AVHRR VIS data. It is more difficult to 

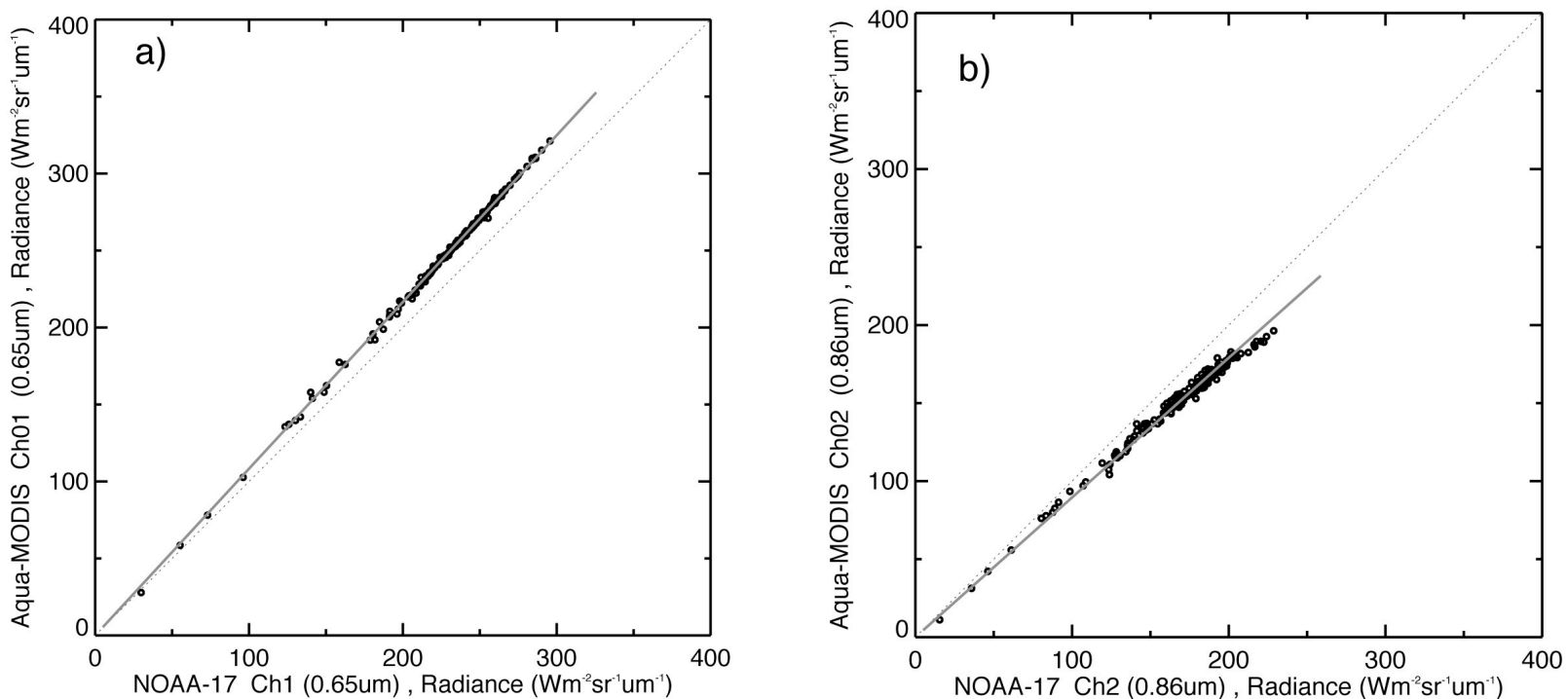

Figure 4: NOAA-17 and Aqua-MODIS matched off-nadir radiances and regression lines, May 2003. (a) $0.65 \mu \mathrm{m}$, regression slope is 1.0911. (b) $0.86 \mu \mathrm{m}$, regression slope is 0.8534 .

make a general conclusion about the method in general because of the complications introduced by the dual gain in $0.86-\mu \mathrm{m}$ channels and the small number of samples and low radiances for the NOAA-17 visible data. For NOAA-17, the DCCT and the inter-calibration method require more monthly points to gain statistical confidence. The MODISbased $0.86-\mu \mathrm{m}$ channel trends should not be compared to the DCCT method until this dual gain issue is resolved.

\section{EFFECTS OF SOLAR ZENITH ANGLE ON DEEP CONVECTIVE CLOUD CALIBRATION}

\subsection{Background}

Once the DCCT has been validated with NOAA 16 and 17 AVHRR data, the goal is to derive gain trends for historical NOAA satellites. One problem that will be encountered, is determining how well DCCT performs under changing solar zenith angle (SZA) conditions, due to the NOAA orbital degradation. Figure 5a shows that the satellites used here cross the equator at SZAs that fluctuate with season around $30^{\circ}$. The NOAA-16 orbit exhibits a slight increase in equatorial SZA during the last 6 months. The current NOAA orbital configuration is not representative of historical orbits. NOAA14 and 15 are more typical of afternoon and morning SZA drifts, respectively. For the first 5 year life-span of NOAA14 , the SZA increased from $30^{\circ}$ to $60^{\circ}$ at the equator and took 3 more years for the ascending and descending node to reverse from day to night. NOAA- 15 was initially launched with a $70^{\circ}$ equatorial SZA. Deep convective clouds become more anisotropic with increasing SZA. Thus, orbital viewing geometry becomes important, since angular sampling is not random. Another problem is to determine the range of SZAs where the DCCT is effective. This determines the number of years that the DCCT can be applied to historical NOAA AVHRR data.

\subsection{DCCT using VIRS data}

The Visible Infrared Scanner (VIRS) instrument onboard the TRMM satellite, precesses every 46 days, essentially sampling all SZAs every 23 days at the equator. The precessing orbit causes the satellite to turn back to the equator at $32^{\circ}$ latitude and restricts the spatial sampling poleward beyond $38^{\circ}$. The maximum view angle on the VIRS imager is $45^{\circ}$. Near the equator where the most of the deep convective clouds are located, the orbit resembles a polar orbiter making it a perfect candidate to test the robustness of the bidirectional and directional models used in the DCCT. The 2$\mathrm{km}$ VIRS $0.65-\mu \mathrm{m}$ channel has had a stable calibration since $1998^{9}$ by virtue of a solar diffuser. VIRS data were collected from January through February and from July through August 2003. Only deep convective cloud pixels were saved, using the same criteria used in Sec. 2.1, but were not limited to the tropical western Pacific and include the zone bounded by $\pm 30^{\circ}$ latitude. The directional model was not applied so that the SZA dependence could be evaluated. All 

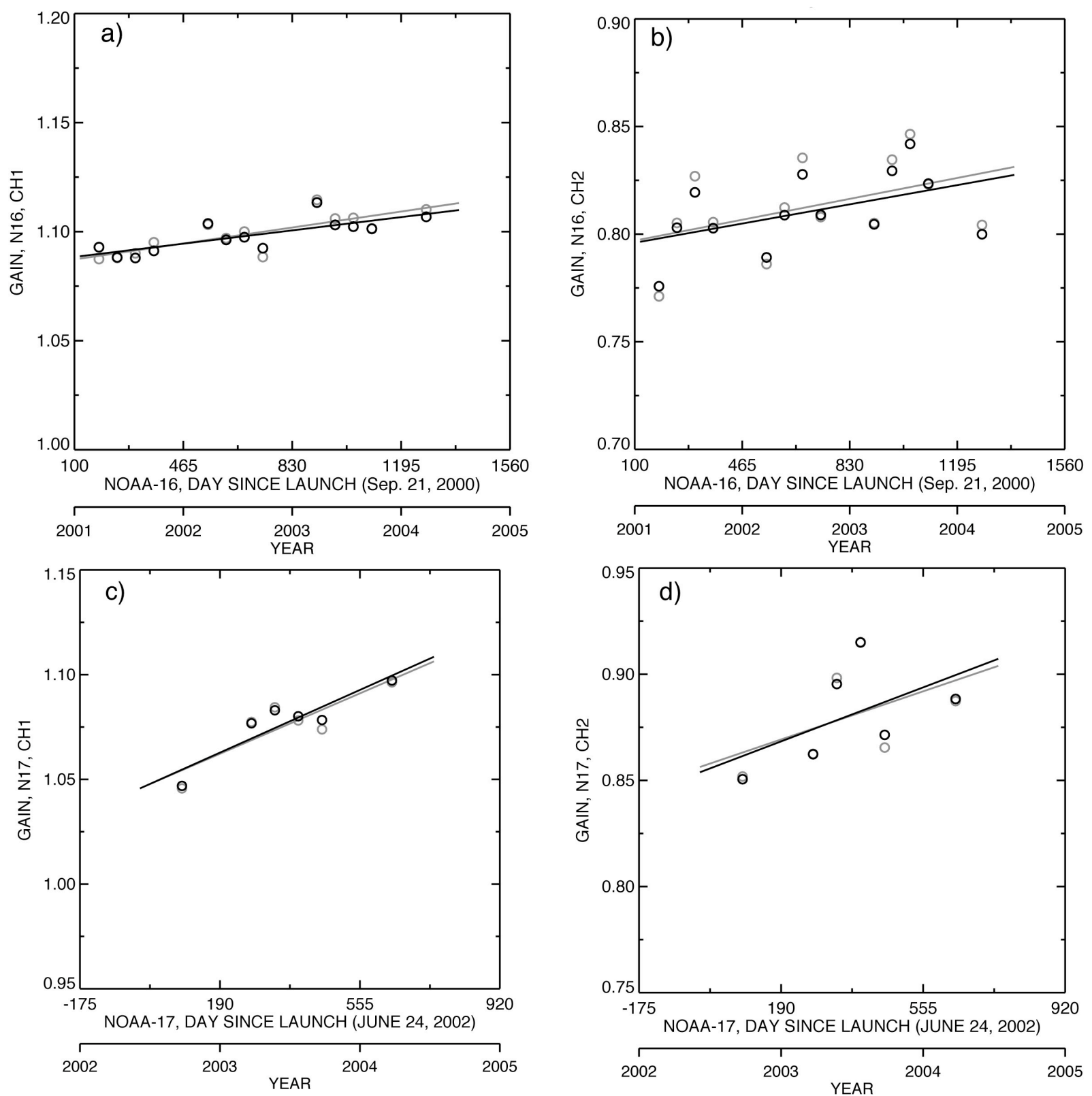

Figure 5: Time series of individual monthly gains with trend lines from matched AVHRR and MODIS radiances; nadir and off-nadir results shown as light and heavy circles and lines, respectively. (a) NOAA-16 $0.65 \mu \mathrm{m}$, (b) NOAA-16 0.86 $\mu \mathrm{m}$, (c) NOAA-17 0.65 $\mu \mathrm{m}$, (d) NOAA-17 $0.86 \mu \mathrm{m}$.

4 months are combined, since the calibration is stable. The PDFs are computed for each $10^{\circ}$ SZA interval from overhead sun to $80^{\circ}$. The mode of the resulting PDFs are then plotted as a function of SZA. Each SZA bin had at least 130,000 pixels for SZA $>20^{\circ}$, shown in Figure $5 \mathrm{~b}$. The radiance is $482.5 \mathrm{Wm}^{-2} \mathrm{sr}^{-1} \mathrm{um}^{-1}$ at $5^{\circ}$ and $437.9 \mathrm{Wm}^{-2}$

Table 2. Annual relative gains in percent based on NOAA-16/Terra and 17/Aqua through April 2004.

\begin{tabular}{ccccc}
\hline Using MODIS & N16 $0.65 \mu \mathrm{m}$ & N16 $0.86 \mu \mathrm{m}$ & N17 $0.65 \mu \mathrm{m}$ & N17 $0.86 \mu \mathrm{m}$ \\
\hline Off-Nadir & 0.609 & 0.893 & 2.99 & 2.54 \\
Nadir & 0.732 & 0.971 & 2.89 & 2.27 \\
\hline
\end{tabular}



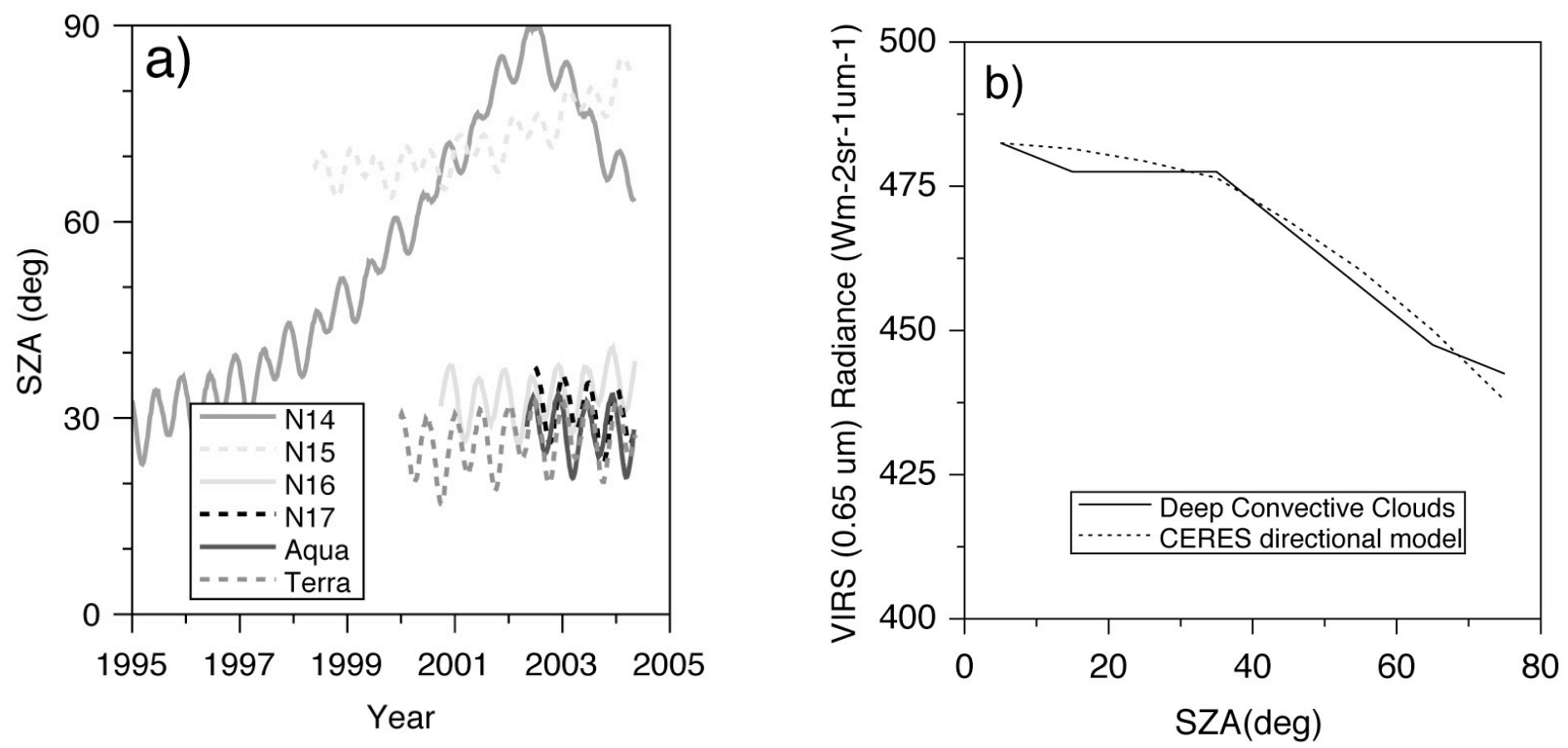

Figure 6: Potential sources of error in DCCT due to SZA. (a) Variation in satellite equatorial SZAs, solid lines indicate afternoon satellites and dotted lines, morning satellites. (b) DCCT radiances (solid line) measured by VIRS and estimated from CERES directional model.

$\mathrm{sr}^{-1} \mu \mathrm{m}^{-1}$ at $75^{\circ}$. This translates to a $9.2 \%$ reduction in radiance. This effect has the potential to cause large biases in the DCCT results. The directional model was applied at each of the $10^{\circ} \mathrm{SZA}$ steps using the radiance of the first SZA bin and is plotted as the dotted line in Figure $6 \mathrm{~b}$. The directional model accurately predicts the change in radiance as a function of SZA for the given viewing geometries of VIRS, which should be similar to those of the AVHRR. Further studies are needed to determine the effects beyond $\mathrm{SZA}=80^{\circ}$. Using $\mathrm{SZA}=80^{\circ}$ as the upper bound for applying the DCCT, NOAA-14 can calibrated for the first 6 years of its lifespan and for first 5 years of NOAA-15. Future work will entail applying DCCT to both morning and afternoon orbiters from NOAA-9 to the present and comparing the relative gain drifts with historical published gains.

\section{CONCLUSIONS}

The preliminary results of the DCCT visible degradations for NOAA-16 are within reason compared to those derived from inter-calibration of AVHRR and MODIS radiances. Before any solid conclusion can be made about the validity of the DCCT, the dual gain of the AVHRR needs to be taken into account, especially in the $0.86 \mu \mathrm{m}$ channel. The DCCT can only estimate the AVHRR high gain mode, while most of the inter-calibration is based on the low gain mode. Prior to NOAA-15, there is only a single gain mode for AVHRR. Thus, using the DCCT to obtain historical gains should be more straightforward. The DCCT, when applied with appropriate angular dependence models, is independent of solar zenith angle oscillations prevalent on NOAA platforms. In the future, the DCCT will be applied to all NOAA satellites from 9 through 17. NOAA AM and PM pairs will be inter-calibrated to transfer the absolute calibration, derived from MODIS/NOAA inter-calibrations. The DCCT will be used to validate the calibration drift for each NOAA satellite.

\section{ACKNOWLEDGMENTS}

This research was funded by the NASA Earth Science Enterprise Clouds and the Earth's Radiant Energy System Project. Additional support was provided by the Environmental Sciences Division of U.S. Department of Energy Interagency Agreement DE-AI02-97ER62341 through the ARM Program. 


\section{REFERENCES}

1. Rao, C. R. N., and J. Chen, Revised post-launch calibration of the visible and near-infrared channels of the Advanced Very High Resolution Radiometer on the NOAA-14 spacecraft. Intl Jour. Remote Sens., 20, 3485-3491, 1999.

2. Loeb, N. G., In-flight calibration of NOAA AVHRR visible and near-IR bands over Greenland and Antarctica. Intl Jour. Remote Sens., 18, 477-490, 1997.

3. Abel, P. and B. Guenther, Calibration results for NOAA-11 AVHRR Channels 1 and 2 from congruent path aircraft observations. J. Atmos. Ocean. Technol. 10, 493-508, 1993.

4. Nguyen, L., P. Minnis, J. K. Ayers and D. R. Doelling, Intercalibration of meteorological satellite imagers using VIRS, ATSR-2 and MODIS. Proc. AMS $11^{\text {th }}$ Conf. Satellite Meteorol. Oceanogr., Madison, WI, Oct. 12-16, 442445, 2001.

5. Doelling, D. R., V. Chakrapani, P. Minnis, L. Nguyen, The calibration of NOAA-AVHRR visible radiances with VIRS. Proc. AMS $11^{\text {th }}$ Conf. Atmos. Radiation, Madison, WI, Oct 15 -18, 614-617, 2001.

6. Hu, Y., B. Wielicki, P. Yang, P. Stackhouse, B. Lin, and D. Young, Application of deep convective cloud albedo observations to satellite-based study of terrestrial atmosphere: monitoring stability of space-borne measurements and assessing absorption anomaly. Accepted, IEEE Trans. Geosci. Remote Sensing, 2004.

7. Priestley, K. J., R. B. Lee III, R. N. Green, S. Thomas, and R.S. Wilson, Radiometric performance of the Clouds and the Earth's Radiant Energy System (CERES) proto-flight model on the Tropical Rainfall Measuring Mission (TRMM) spacecraft for 1998. Proc. AMS 10th Conf. Atmos. Rad., Madison, WI, June 28-July 2, 33-36, 1999.

8. Loeb, N. G., N. Manalo-Smith, S. Kato, W. F. Miller, S. K. Gupta, P. Minnis, and B. A. Wielicki, Angular distribution models for top-of-atmosphere radiative flux estimation from the Clouds and the Earth's Radiant Energy System instrument on the Tropical Rainfall Measuring Mission satellite. Part. 1: Methodology. J. Appl. Meteorol., 42, 240-265, 2003.

9. Minnis, P., L. Nguyen, D. R. Doelling, D. F. Young, W. F. Miller, Rapid calibration of operational and research meteorological satellite imagers, Part I: Use of the TRMM VIRS or ERS-2 ATSR-2 as a reference. J. Atmos. Ocean. Technol. 19, 1233-1249, 2002. 